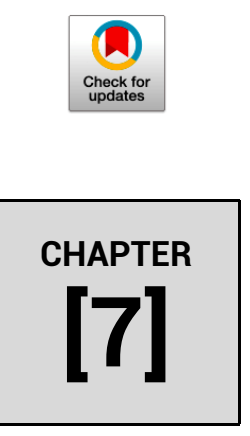

In: Environmental Degradation: Causes and Remediation Strategies

DOI: 10.26832/aesa-2020-edcrs-07

\title{
SWOT analysis of agro-waste based adsorbents for persistent dye pollutants removal from wastewaters
}

\author{
Bashir Adelodun ${ }^{1,2, *}$, Fidelis Odedishemi Ajibade ${ }^{3,4}$, \\ Taofeeq Sholagberu Abdulkadir ${ }^{\prime}$, \\ Hashim Olalekan Bakare ${ }^{6}$ and Kyung Sook Choi ${ }^{1,7, *}$
}

\footnotetext{
${ }^{1}$ Department of Agricultural Civil Engineering, Kyungpook National University, Daegu, Korea ${ }^{2}$ Department of Agricultural and Biosystems Engineering, University of Ilorin, PMB 1515, Ilorin, Nigeria ${ }^{3}$ Department of Civil and Environmental Engineering, Federal University of Technology, Akure, Nigeria ${ }^{4}$ Research Centre for Eco-Environmental Sciences, Chinese Academy of Sciences, Beijing 100085, China ${ }^{5}$ Department of Water Resources and Environmental Engineering, University of Ilorin, PMB 1515, Ilorin, Nigeria ${ }^{6}$ Department of Chemical Engineering, University of Ilorin, PMB 1515, Ilorin, Nigeria ${ }^{7}$ Institute of Agricultural Science \& Technology, Kyungpook, National University, Daegu, Korea
}

ABSTRACT

Dyes, especially from textile industries, are significant pollutants in water and wastewater, which have become pervasive in the environs to which they are discharged. The effluents containing different types of dyes have become ubiquitous in the environment. While several treatment techniques have been developed to address the removal of recalcitrant dyes from water and wastewater, the adsorption technique is highly preferred due to its many advantages. However, selecting the appropriate alternative adsorbents with high adsorption capacity to costly activated carbon has continued to receive great attention. This book chapter reviewed the applicability of adsorptive techniques of agro-waste based adsorbents for the removal of dye pollutants from water and wastewater. The mechanisms of persistent dye pollutant removals based on the adsorption processes were adequately described. Further, the strengths, weaknesses, opportunities and threats (SWOT) of using agro-waste materials as alternative adsorbents are also accounted.

KEYWORDS Agro-waste adsorbent, Dye pollutants, Adsorption mechanism, SWOT analysis

B] Bashir Adelodun; Kyung Sook Choi, Email: adelodun.b@unilorin.edu.ng; ks.choi@knu.ac.kr (C) 2020 | Agro Environ Media | Agriculture and Environmental Science Academy, Haridwar, India 


\section{Introduction}

Due to the global water resources scarcity, the reuse of wastewater has recently been considered as a sustainable alternative to address the increasingly stiff competition of the limited resource, especially for agricultural activities, in many water-scarce regions (Libutti et al., 2018; Mounira et al., 2016). Hence, the need to ensure the adequacy of the quality of the treated wastewater for irrigation purposes and sustainable aquatic ecosystems (Kumar et al., 2019; Adewumi and Ajibade, 2019; Baharvand and Mansouri Daneshvar, 2019). However, the increasing discharge of the generated wastewater into the environment without adequate treatment has been an utmost concern as it is related to human health and potential threats to aquatic lives (Lim and Aris, 2014). The rising population, changing consumption patterns and advances in industrialization are a few of many factors that are continually changing the diversities, patterns and quantities of wastewater generation. Moreover, the diversity of the wastewater sources have hindered the efficiency of some of the targeted treatment techniques. For instance, organic pollution generated from organic compounds originates from diverse sources, including domestic sewage, municipal wastewater, urban run-off and agricultural and industrial effluents (Adelodun et al., 2019; Rashed, 2013). Most of the persistent organic pollutants are products of daily anthropogenic activities that have widespread in the environment (Katsoyiannis and Samara, 2004).

Although organic pollutants can be traced to various sources, wastewaters from industrial discharges are, however, regarded as highly toxic, carcinogenic and contain persistent organic pollutants (Doruk et al., 2016). The industrial activities, especially textile processing is one of the high water-intensives which aided pollution of water bodies with high concentrations of dyes, total dissolved solids, chemical oxygen demand, biochemical oxygen demand, heavy metals, surfactants and many other toxic organic compounds and also contributes to the depletion of available water resources (Vergili et al., 2012; Tehrani-Bagha et al., 2010; Salleh et al., 2011). Among these organic pollutants, dyes are found to be the most common, recalcitrant, challenging to biodegrade and noxious pollutants (Peng et al., 2016; Ali et al., 2019).

The effluents containing different types of dyes have become ubiquitous in the environment as they can be found in the point source discharges of most of the industries, including textiles, paper and pulp, pharmaceutical, tannery, paint, food and et cetera. The dye pollutants pose undesirability in the aesthetic, obstructing sunlight into the water and degradation of the water environment where they are discharged (Nidheesh et al., 2018). In fact, the excessive use of dyes has been linked to the various sources from which the persistent organic pollutants are produced (Shalla et al., 2018).

Textile industries are the major sources of organic dyes. The dyeing operations, a significant component of textile activities, involve the use of poorly biodegradable dyes and other auxiliary 
organic materials, including soda ash, detergents and salts (Vergili et al., 2012), which produce mutagenic and carcinogenic byproducts (Iqbal, 2016). The complexities in molecular structures of dye chemicals and the recalcitrant nature of textile effluents due to their diversity from manufacturing processes of different forms of textile products require highly efficient treatment techniques.

These treatment techniques and materials need to be affordable and be able to provide solutions to reuse the treated wastewater without any potential health-related issues to both humans and ecosystems. For these reasons, the treatment techniques, with high efficiency without secondary waste, are limited. Nevertheless, considering the toxicity of organic dye pollutants to our environment, both human and aquatic, it has, therefore, become increasingly important to intensify efforts towards the treatment of effluent containing dyes before their discharge into water bodies. Moreover, the reuse of adequately treated wastewater from textile industries can address the scarcity of water resources in the regions on concerns.

There has been rapid development in the treatment of wastewater containing dye pollutants in recent times. Consequently, several treatment techniques have been developed for their removal from water and wastewater. These include coagulation, biological treatment, chemical oxidation, electrochemical and membrane processes, aerobic microbial degradation and adsorption (Salleh $e t$ al., 2011). While some of the methods are touted to be relatively effective, they are however expensive, high energy demand, incapable of removing different variety of dyes effectively and are found to produce byproducts which require further treatment (De Andrade et al., 2018; Mezohegyi et al., 2012; Pokhrel and Viraraghavan, 2004).

Moreover, some of these treatment techniques have limited applications in many parts of developing counties where indiscriminate point source discharges of persistent organic pollutants from industries, including dyes, persist (UNESCO, 2017). However, adsorption method is generally found to be effective for the removal of recalcitrant organic pollutants, including different forms of dyes, due to its simple operating design and conditions, no sort of unwelcoming secondary wastes and low cost of operations especially when non-conventional alternative adsorbents are used (Siddiqui et al., 2019; Chang et al., 2017).

The quality of the treated dye effluents largely depends on the type of adsorbents used and welldesigned sorption processes, among many other factors (Salleh et al., 2011). The major problem lies in selecting the appropriate adsorbents with an applicable adsorptive technique for the removal of dye pollutants from water and wastewater (Gupta and Suhas, 2009). This study, therefore, aimed to review the selected agro-waste based adsorbents used for the treatment or remediation of selected persistent organic dyes with their corresponding adsorptive techniques. In this study, we described and comprehensively compared some conventional adsorbents based on the strength of the adsorptive technique, used to remediate the wastewater pollution containing dye pollutants using the SWOT analysis. 


\section{Adsorption mechanisms for dyes removal from wastewater}

Adsorption refers to the accumulation of pollutants, including dyes in the wastewater at the surface of the adsorbents. The physical and chemical interactions of adsorption processes occur at the interface of the two media i.e., adsorbent and wastewater. The pollutant molecules that are retained on the surface during the adsorption process are referred to as adsorbates while the materials upon which they are retained are called adsorbents. The bonding of adsorbates on the adsorbent surface is characterized by either Van der Waals, electrostatics and /or hydrogen bonds due to the presence of both carbonyl and hydroxyl groups on the adsorbents (Wakkel et al., 2019).

Several factors aid the adsorption performance of any selected adsorbent in removing pollutants from wastewater. Aside the absorbent properties including high carbon or oxygen contents required of a suitable absorbent, other characteristics include large surface area with porous structure, high abrasion resistance and thermal stability and other operating conditions such as adsorbent dose, contact time, $\mathrm{pH}$ of the wastewater containing the dye pollutants and initial dye concentration (Ali et al., 2012; Chandane and Singh, 2016; Aljeboree et al., 2017).

\section{Adsorption kinetics}

The adsorption kinetics is a process used to investigate the adsorption mechanism. The adsorption rate using the kinetic study evaluates the best material choice of the adsorbent. The process explores the important kinetic parameters responsible for the sorption rate of the dye pollutants by the adsorbent. Further, the efficiency of the adsorption process can be assessed while also enable its applicability to industrial use and commercial applications. The kinetic models that are mostly used to describe adsorption mechanism for the dye pollutants removal are pseudo-first-order for simple adsorption kinetic analysis (Lagergren, 1898), pseudo-second-order based on adsorption equilibrium capacity (Ho and McKay, 1999), Elovich for chemisorption processes and also applicable to systems with heterogeneous adsorption surface (Low, 1960) and intra-particle diffusion for the identification of diffusion mechanism (Weber, 1963), using Eqs. (1) to (5).

$$
\begin{aligned}
& q_{t}=q_{B}\left[1-\exp \left(-k_{1} t\right)\right] \\
& q_{t}=\frac{k_{s} q_{E}^{2} t}{1+k_{s} q_{E} t} \\
& h_{0}=k_{s} q_{\theta}^{2}
\end{aligned}
$$




$$
\begin{aligned}
& q_{t}=\left(\frac{1}{\beta}\right) \ln (\propto, \beta)+\left(\frac{1}{\beta}\right) \ln (t) \\
& q_{t}=k_{i d} \sqrt{t}+1
\end{aligned}
$$

where $q_{t}\left(\mathrm{mg} \mathrm{g}^{-1}\right)$ is the amount of dye pollutants adsorbed at time $t ; q_{e}\left(\mathrm{mg} \mathrm{g}^{-1}\right)$ is the adsorption capacity of the dye pollutants at equilibrium; $k_{1}\left(\mathrm{~min}^{-1}\right), k_{s}\left(\mathrm{~g} \mathrm{gm}^{-1}\right)$ and $k_{i d}\left(\mathrm{mg} \mathrm{g}^{-1} \mathrm{~min}^{-1 / 2}\right)$ are the adsorption rate constants for pseudo-first-order, pseudo-second-order and intra-particle diffusion models, respectively; $t(\mathrm{~min})$ is the contact time; $h_{0}\left(\mathrm{mg} \mathrm{g}^{-1} \mathrm{~min}^{-1}\right)$ is the initial sorption rate which can be obtained when approaches zero value.

\section{Adsorption isotherms}

The adsorption capacity can be enhanced using different forms of activation methods, which involve either physical activation such as carbonization of material or chemical activation using chemical activating agents (Adegoke and Bello, 2015). The effectiveness of the adsorption mechanisms in terms of relative adsorption capacity and equilibrium concentration of adsorbent through its interactions with adsorbate can be described using adsorption isotherms. The dye pollutant distribution between the two inter-surface media can be described using adsorption isotherm at a particular temperature when the equilibrium is reached (Aljeboree et al., 2017). The commonly used adsorption isotherms are:

Freundlich isotherm is an empirical model that describes the multilayer adsorption based on the assumption of energy distribution on the adsorption surface (Freundlich and Heller, 1939). The adsorption rate varies with the strength of energy on the adsorption surface. The Freundlich isotherm model is expressed by the Eq. (6).

$$
q_{e}=K_{f} \cdot C_{e}^{1 / n}
$$

where $q_{e}\left(\mathrm{mg} \mathrm{g}^{-1}\right)$ is the unit adsorption capacity; $C_{e}(\mathrm{mg} / \mathrm{L})$ is the dye concentration at equilibrium; $K_{f}$ and $n\left[\mathrm{mg} \mathrm{g}^{-1}\left(\mathrm{~L} \mathrm{mg}^{-1}\right)^{n}\right]$ are Freundlich constants.

Langmuir isotherm model is based on the monolayer adsorption on the homogeneous surface with weak intermolecular forces (Langmuir, 1918). It is assumed that the adsorption rate decreases with increasing dye molecules on the adsorption surface (Aljeboree et al., 2017). The Langmuir isotherm model is represented using Eq. (7).

$$
q_{e}=\frac{q_{\max } K_{L} c_{e}}{1+K_{L} c_{e}}
$$

where $q_{\max }$ is maximum dye pollutants adsorbed; $K_{L}\left(\mathrm{~L} \mathrm{mg}^{-1}\right)$ is the Langmuir constant for adsorption energy and binding affinity of the adsorption surface. 
Tempkin isotherm model describes the interaction effects of both adsorbent and adsorbate based on the assumption that the strength of energy on the adsorption surface decreases with coverage (Tempkin and Pyzhev, 1940). The Tempkin isotherm model is expressed using Eq. (8).

$$
q_{e}=\frac{k T}{b} \log \left(K_{T} C_{e}\right)
$$

where $b\left(\mathrm{~kJ} \mathrm{~mol}^{-1}\right)$ and $K_{T}\left(\mathrm{~L} \mathrm{mg}^{-1}\right)$ are the Temkin constants for adsorption energy and maximum binding energy, respectively. The detailed wide-ranging of isotherm models that have been extensively employed over the years is presented in Table 1.

\section{Agricultural waste-based adsorbents for removal of dye pollutants}

There have been several developed adsorbent materials for the removal of dyes from water and wastewater, with activated carbon regarded as the best of all and highly preferred (Martins and Nunes, 2015). However, the high cost of procurement, sludge production and regeneration problem have been the most significant constraints in the use of activated carbon as pollutant removal, including dyes. Moreover, Walker et al. (2003) reported the ineffectiveness of the activated carbon in the removal of both disperse and vat classes of dyes. The locally-sourced agricultural waste materials with high pollutant binding capacities have, however, been suggested and explored as alternative low-cost adsorbents (Salleh et al., 2011; Adegoke and Bello, 2015).

Agricultural wastes are discarded in large quantities and these include rice husk, maize cob, peanut husk, soybean hull, eggshell, sesame hull, potato peels, citrus peels and many more. The agro-waste can be classified into plant-based and animal-based, depending on the origin of the waste materials. Living organisms such as algal and microbial biomass were also reported to have been used as pollutant adsorbents in water treatment (Siddiqui et al., 2019). The agro-waste based adsorbents are used either in their raw forms or as composites for the removal of different classes of dyes. The presence of functional carboxyl, carbonyl and hydroxyl groups present at the surface of the agricultural wastes make them suitable adsorbent candidates for dye removal, most notably the cationic dyes (Salleh et al., 2011; Wakkel et al., 2019).

The removal of various types of dyes using some selected agro-waste based adsorbents with their adsorption capacities is presented in Table 2. The adsorption capacities were observed to vary significantly among the different adsorbents used in removing different dye pollutants, while adsorption mechanisms for which the maximum adsorption capacities occurred were mostly based on Pseudo-second order for adsorption kinetic and Freundlich and Langmuir for adsorption isotherms. 


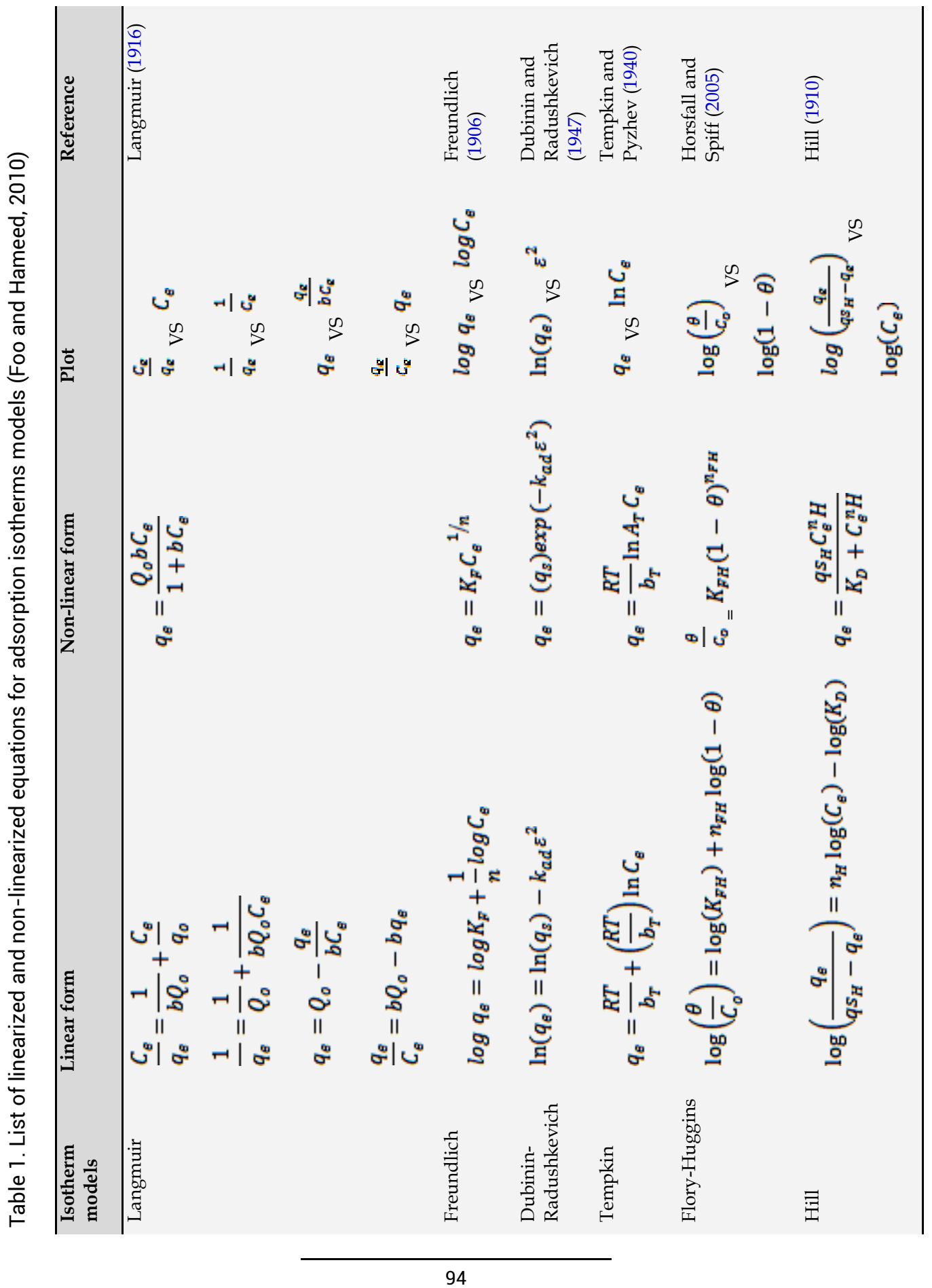




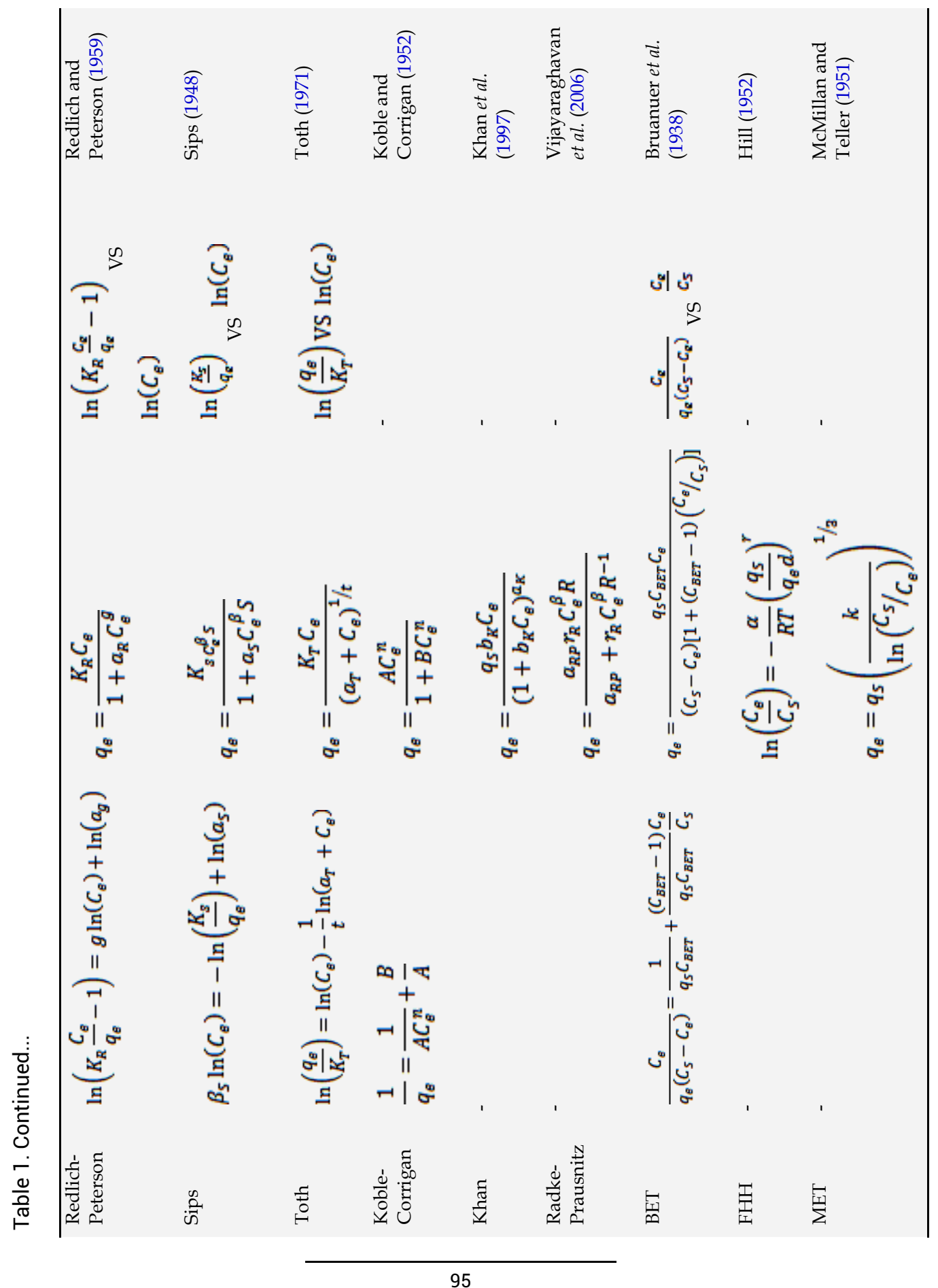




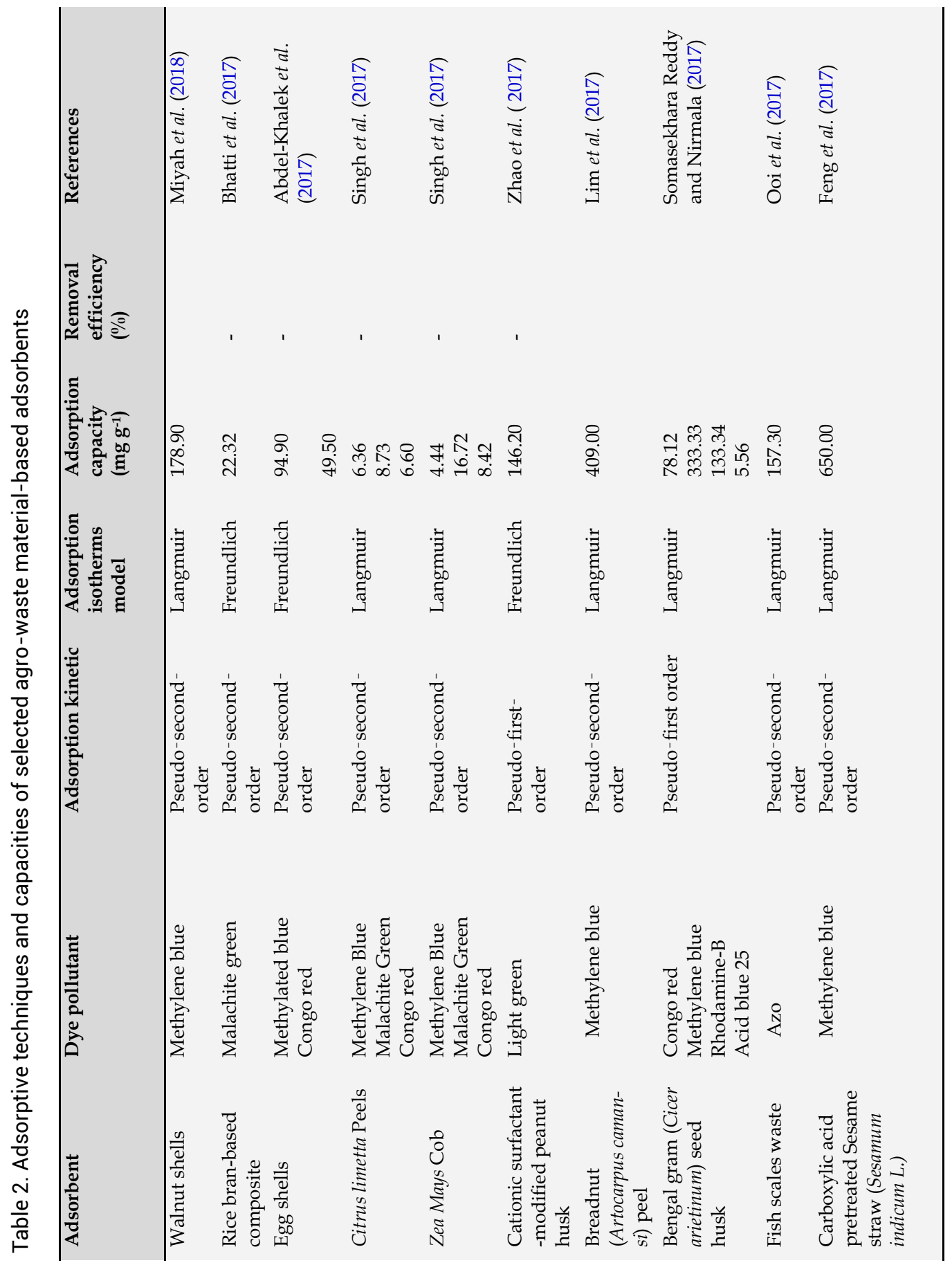




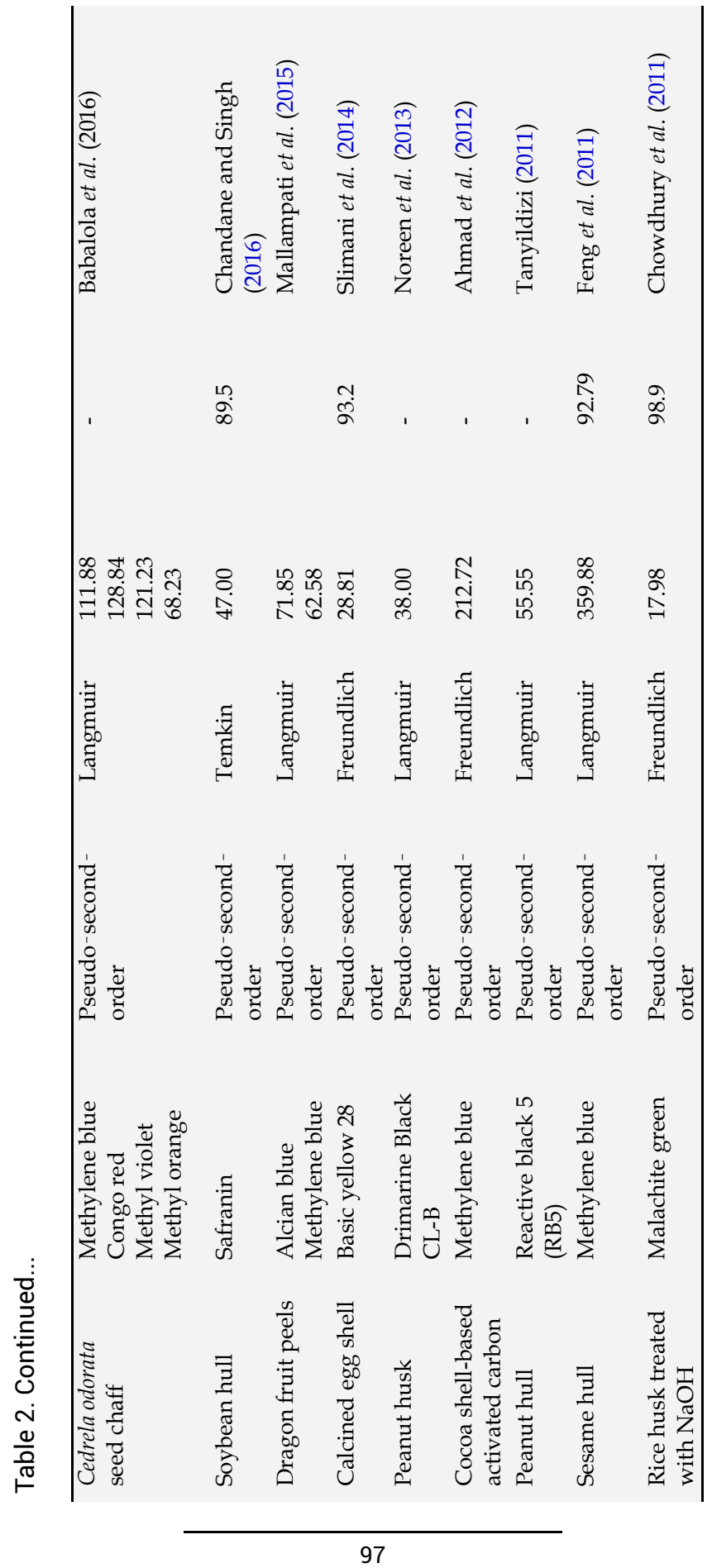




\section{SWOT analysis and perspectives}

The summary of strengths, weaknesses, opportunities and threats of the agro-waste based adsorbents for the removal of dye pollutants from water and wastewater is presented in Table 3. The analysis indicated the use of agricultural waste as adsorbents for dye removals are highly beneficial not only in terms of water and wastewater treatment of dye pollutants but also as an opportunity for waste management. The agricultural waste materials are generated in large quantities and are of zero economic value, constituting environmental burdens. They are considered as the best alternative to other costly material based adsorbents.

Table 3. SWOT analysis of the agro-waste based adsorbents as dye pollutant removal.

\begin{tabular}{ll}
\hline Strength \\
\hline - & Applicability to remove variety of dyes \\
& (Babalola et al., 2016).
\end{tabular}

- Relatively cheap to procure the materials (Chowdhury et al., 2011).

- $\quad$ Readily available (Bhatti et al., 2017).

- It is energy efficient process (AbdelKhalek et al., 2017).

- Relatively good equilibrium time and rapid kinetics (Adegoke and Bello, 2015).

- High carbon content (Singh et al., 2017).

- Good biodegradable and regeneration properties (Singh et al., 2017).

\section{Weakness}

- Chemical activation using $\mathrm{NaOH}, \mathrm{KOH}$, $\mathrm{ZnCl}_{2}$, etc are required to improve porous structure of the adsorbents (Abdolali et al., 2014).

- Adsorption capacity of the same adsorbent vary with different dye pollutants removal (Abdel-Khalek et al., 2017).

- Not all the agro-wastes adsorbent based perform efficiently under natural conditions (Zhao et al., 2017).

\begin{tabular}{|c|c|}
\hline Opportunities & Threats \\
\hline $\begin{array}{l}\text { Valorization of agricultural waste with } \\
\text { low economic values. } \\
\text { Disposal problems associated with } \\
\text { agricultural waste is reduced (Babalola et } \\
\text { al., 2016). } \\
\text { - Cost of disposal of agricultural waste is } \\
\text { eliminated. } \\
\text { - Commercialization of agricultural waste } \\
\text { as excellent adsorbent. } \\
\text { High profitability when explored at } \\
\text { industrial scale. }\end{array}$ & $\begin{array}{l}\text { Spent adsorbents and removed dyes } \\
\text { could cause environmental } \\
\text { discomfort if not properly managed } \\
\text { (Adegoke and Bello, 2015). } \\
\text { Adjustment of pH level for optimum } \\
\text { adsorption process using some } \\
\text { chemicals can create economic } \\
\text { burdens on the use of agro-waste } \\
\text { materials as adsorbent for dye } \\
\text { pollutant removal (Lim and Aris, 2014). } \\
\text { Activation process using chemicals to } \\
\text { improve the porous structure of some } \\
\text { agro-waste materials require technical } \\
\text { expertise. }\end{array}$ \\
\hline
\end{tabular}


Similarly, the adsorbents made from agro-wastes are efficient and the processes required to convert them to adsorbents are eco-friendly as they can be produced without going through any industrial process. Despite the numerous advantages of agricultural waste materials as adsorbents for dye pollutants removal, some plant-based agro-wastes, though with functional cellulose structures for trapping the pollutants, are found to release some toxic organic compounds into the water bodies being treated. The release of organic carbon can cause further deterioration of water quality through enhancement of the biological oxygen demand, chemical oxygen demand and total organic carbon contents.

Further, the adsorbents made from plant-based agro-wastes tend to attain saturation faster due to the coverage of interface by the dye molecules, thereby preventing further adsorption process. Although altering the $\mathrm{pH}$ of the dye solution using either acid or base can offer solutions to the stated problem, this process, however, requires technical expertise and costly instrumentation to achieve the desorption before regeneration occurs (Siddiqui et al., 2017). Modifications of agro-waste through chemical pretreatments or their usage in composites form were reported to have enhanced adsorption capacities, unlike when the agro-waste materials are used as adsorbents in their raw forms (Feng et al., 2017; Chowdhury et al., 2011). However, this assertion is only applicable to some selected agro-waste materials targeting particular dye pollutant classes or types.

\section{Conclusion}

This study explored the use of agricultural waste materials as adsorbents for the removal of dye pollutants in wastewater and water treatment. The detailed review of the literature was carried out on the adsorption mechanisms of selected agricultural waste-based adsorbents considering different adsorption kinetics and isotherms with their corresponding adsorption capacities. The SWOT analysis was further carried out, highlighting some of the advantages and disadvantages of using agro-waste based adsorbents for the removal of persistent organic dye pollutants under their strengths and opportunities and weaknesses and threats, respectively. While there are abundant of agro-waste materials, including both plant and animal origins, which have been used as adsorbents, particularly to treat dye polluted wastewater, the adsorption capacities were found to vary widely with different dye pollutants. Meanwhile, the Pseudo-second-order type of adsorption kinetics and both Langmuir and Freundlich isotherm models resulted in maximum adsorption capacity of different dye pollutants among the majority of the agro-waste based adsorbents. The SWOT analysis revealed some disadvantages of using agro-waste materials as adsorbents for dye pollutant treatment, which are majorly on some improvements required to enhance the adsorption capacity. However, the advantages which are based on the strengths and 
opportunities outweigh the weaknesses and threats associated with the use of agro-waste based adsorbents, which make them highly preferred as sustainable materials for the treatment of dye polluted water and wastewater.

\section{References}

Abdel-Khalek, M.A., Abdel Rahman, M.K. and Francis, A.A. (2017). Exploring the adsorption behavior of cationic and anionic dyes on industrial waste shells of egg. Journal of Environmental Chemical Engineering, 5(1): 319-327. https://doi.org/10.1016/j.jece.2016.11.043

Abdolali, A., Guo, W.S., Ngo, H.H., Chen, S.S., Nguyen, N.C. and Tung, K.L. (2014). Typical lignocellulosic wastes and byproducts for biosorption process in water and wastewater treatment: A critical review. Bioresource Technology, 160: 5766. https://doi.org/10.1016/j.biortech.2013.12.037

Adegoke, K.A. and Bello, O.S. (2015). Dye sequestration using agricultural wastes as adsorbents. Water Resources and Industry, 12: 8-24. https://doi.org/10.1016/j.wri.2015.09.002

Adelodun, B., Ajibade, O.F., Segun, M. and Choi, K.S. (2019). Dosage and settling time course optimization of Moringa oleifera in municipal wastewater treatment using response surface methodology. Desalination and Water Treatment, 167: 45-56. https://doi.org/10.5004/dwt.2019.24616

Adewumi, J.R. and Ajibade, F.O. (2019). Periodic determination of physicochemical and bacteriological characteristics of wastewater effluents for possible reuse as irrigation water. International Journal of Energy and Water Resources, 3(4): 269276. https://doi.org/10.1007/s42108-019-00036-6

Ahmad, F., Daud, W.M.A.W., Ahmad, M.A. and Radzi, R. (2012). Cocoa (Theobroma cacao) shell-based activated carbon by $\mathrm{CO}_{2}$ activation in removing of Cationic dye from aqueous solution: Kinetics and equilibrium studies. Chemical Engineering Research and Design, 90(10): 1480-1490. https://doi.org/10.1016/j.cherd.2012.01.017

Ali, I., Asim, M. and Khan, T.A. (2012). Low cost adsorbents for the removal of organic pollutants from wastewater. Journal of Environmental Management, 113: 170-183. https://doi.org/10.1016/j.jenvman.2012.08.028

Ali, I., Basheer, A.A., Mbianda, X.Y., Burakov, A., Galunin, E., Burakova, I. and Grachev, V. (2019). Graphene based adsorbents for remediation of noxious pollutants from wastewater. Environment International, 127: 160-180. https:// doi.org/10.1016/j.envint.2019.03.029

Aljeboree, A.M., Alshirifi, A.N. and Alkaim, A.F. (2017). Kinetics and equilibrium study for the adsorption of textile dyes on coconut shell activated carbon. Arabian Journal of Chemistry, 10: S3381-S3393. https://doi.org/10.1016/ j.arabjc.2014.01.020

Babalola, J.O., Koiki, B.A., Eniayewu, Y., Salimonu, A., Olowoyo, J.O., Oninla, V.O. and Omorogie, M.O. (2016). Adsorption efficacy of Cedrela odorata seed waste for dyes: Non linear fractal kinetics and non linear equilibrium studies. Journal of Environmental Chemical Engineering, 4(3): 3527-3536. https://doi.org/10.1016/j.jece.2016.07.027

Baharvand, S. and Mansouri Daneshvar, M.R. (2019). Impact assessment of treating wastewater on the physiochemical variables of environment: a case of Kermanshah wastewater treatment plant in Iran. Environmental Systems Research, 8 (1). https://doi.org/10.1186/s40068-019-0146-0

Bhatti, H.N., Jabeen, A., Iqbal, M., Noreen, S. and Naseem, Z. (2017). Adsorptive behavior of rice bran-based composites for malachite green dye: Isotherm, kinetic and thermodynamic studies. Journal of Molecular Liquids, 237: 322-333. https:// doi.org/10.1016/j.molliq.2017.04.033

Chandane, V. and Singh, V. K. (2016). Adsorption of safranin dye from aqueous solutions using a low-cost agro-waste material soybean hull. Desalination and Water Treatment, 57(9): 4122-4134. https:// doi.org/10.1080/19443994.2014.991758

Chang, R., Jien, S.H., Weng, C.H., Lee, T.W. and Liao, C. Sen. (2017). Fast removal of polybrominated diphenyl ethers from aqueous solutions by using low-cost adsorbents. Sustainability (Switzerland), 9(1): 1-11. https://doi.org/10.3390/ 
su9010102

Chowdhury, S., Mishra, R., Saha, P. and Kushwaha, P. (2011). Adsorption thermodynamics, kinetics and isosteric heat of adsorption of malachite green onto chemically modified rice husk. Desalination, 265(1-3): 159-168. https:// doi.org/10.1016/j.desal.2010.07.047

De Andrade, J.R., Oliveira, M.F., Da Silva, M.G.C. and Vieira, M.G.A. (2018). Adsorption of Pharmaceuticals from Water and Wastewater Using Nonconventional Low-Cost Materials: A Review. Industrial and Engineering Chemistry Research, 57(9): 3103-3127. https://doi.org/10.1021/acs.iecr.7b05137

Doruk, N., Yatmaz, H.C. and Dizge, N. (2016). Degradation Efficiency of Textile and Wood Processing Industry Wastewater by Photocatalytic Process Using In Situ Ultrafiltration Membrane. Clean - Soil, Air, Water, 44(3): 224-231. https:// doi.org/10.1002/clen.201400203

Feng, Y., Liu, Y., Xue, L., Sun, H., Guo, Z., Zhang, Y. and Yang, L. (2017). Carboxylic acid functionalized sesame straw: A sustainable cost-effective bioadsorbent with superior dye adsorption capacity. Bioresource Technology, 238(50): 675-683. https://doi.org/10.1016/j.biortech.2017.04.066

Feng, Y., Yang, F., Wang, Y., Ma, L., Wu, Y., Kerr, P.G. and Yang, L. (2011). Basic dye adsorption onto an agro-based waste material - Sesame hull (Sesamum indicum L.). Bioresource Technology, 102(22): 10280-10285. https://doi.org/10.1016/ j.biortech.2011.08.090

Freundlich, H. and Heller, W. (1939). The Adsorption of cis- and trans-Azobenzene. Journal of the American Chemical Society. https://doi.org/10.1021/ja01877a071

Gupta, V.K. and Suhas. (2009). Application of low-cost adsorbents for dye removal - A review. Journal of Environmental Management, 90(8): 2313-2342. https://doi.org/10.1016/j.jenvman.2008.11.017

Ho, Y.S. and McKay, G. (1999). Pseudo-second order model for sorption processes. Process Biochemistry, 34: 451-465. https:// doi.org/10.1021/acs.oprd.7b00090

Iqbal, M. (2016). Vicia faba bioassay for environmental toxicity monitoring: A review. Chemosphere, 144: 785-802. https:// doi.org/10.1016/j.chemosphere.2015.09.048

Katsoyiannis, A. and Samara, C. (2004). Persistent organic pollutants (POPs) in the sewage treatment plant of Thessaloniki, northern Greece: Occurrence and removal. Water Research, 38(11): 2685-2698. https://doi.org/10.1016/ j.watres.2004.03.027

Kumar, V., Thakur, R.K. and Kumar, P. (2019). Assessment of heavy metals uptake by cauliflower (Brassica oleracea var. botrytis) grown in integrated industrial effluent irrigated soils: A prediction modeling study. Scientia Horticulturae, 257, 108682. https://doi.org/10.1016/j.scienta.2019.108682

Lagergren, S.K. (1898). About the theory of so-called adsorption of soluble substances. Sven. Vetenskapsakad. Handingarl.

Langmuir, I. (1918). The adsorption of gases on plane surfaces of glass, mica and platinum. Journal of the American Chemical Society. https://doi.org/10.1021/ja02242a004

Libutti, A., Gatta, G., Gagliardi, A., Vergine, P., Pollice, A., Beneduce, L. and Tarantino, E. (2018). Agro-industrial wastewater reuse for irrigation of a vegetable crop succession under Mediterranean conditions. Agricultural Water Management, 196: 1-14. https://doi.org/10.1016/j.agwat.2017.10.015

Lim, A.P. and Aris, A.Z. (2014). A review on economically adsorbents on heavy metals removal in water and wastewater. Reviews in Environmental Science and Biotechnology, 13(2): 163-181. https://doi.org/10.1007/s11157-013-9330-2

Lim, L.B.L., Priyantha, N., Tennakoon, D.T.B., Chieng, H.I., Dahri, M.K. and Suklueng, M. (2017). Breadnut peel as a highly effective low-cost biosorbent for methylene blue: Equilibrium, thermodynamic and kinetic studies. Arabian Journal of Chemistry, 10: S3216-S3228. https://doi.org/10.1016/j.arabjc.2013.12.018

Low, M. J. D. (1960). Kinetics of chemisorption of gases on solids. Chemical Reviews, 60(3): 267-312. https://doi.org/10.1021/ cr60205a003

Mallampati, R., Xuanjun, L., Adin, A. and Valiyaveettil, S. (2015). Fruit peels as efficient renewable adsorbents for removal of dissolved heavy metals and dyes from water. ACS Sustainable Chemistry and Engineering, 3(6): 1117-1124. https:// doi.org/10.1021/acssuschemeng.5b00207

Martins, A. and Nunes, N. (2015). Adsorption of a textile dye on commercial activated carbon: A simple experiment to 
explore the role of surface chemistry and ionic strength. Journal of Chemical Education, 92(1): 143-147. https:// doi.org/10.1021/ed500055v

Mezohegyi, G., van der Zee, F.P., Font, J., Fortuny, A. and Fabregat, A. (2012). Towards advanced aqueous dye removal processes: A short review on the versatile role of activated carbon. Journal of Environmental Management, 102: 148-164. https://doi.org/10.1016/j.jenvman.2012.02.021

Miyah, Y., Lahrichi, A., Idrissi, M., Khalil, A. and Zerrouq, F. (2018). Adsorption of methylene blue dye from aqueous solutions onto walnut shells powder: Equilibrium and kinetic studies. Surfaces and Interfaces, 11: 74-81. https:// doi.org/10.1016/j.surfin.2018.03.006

Mounira, C., Seddini, A. and Benameur, S. (2016). Relieving the water shortage crisis of Algeria by reusing treated wastewater lagoons. Desalination and Water Treatment, 57(32): 15250-15262. https://doi.org/10.1080/19443994.2015.1070752

Nidheesh, P.V., Zhou, M. and Oturan, M.A. (2018). An overview on the removal of synthetic dyes from water by electrochemical advanced oxidation processes. Chemosphere, 197: 210-227. https://doi.org/10.1016/ j.chemosphere.2017.12.195

Noreen, S., Bhatti, H.N., Nausheen, S., Sadaf, S. and Ashfaq, M. (2013). Batch and fixed bed adsorption study for the removal of Drimarine Black CL-B dye from aqueous solution using a lignocellulosic waste: A cost affective adsorbent. Industrial Crops and Products, 50: 568-579. https://doi.org/10.1016/j.indcrop.2013.07.065

Ooi, J., Lee, L. Y., Hiew, B. Y. Z., Thangalazhy-Gopakumar, S., Lim, S. S. and Gan, S. (2017). Assessment of fish scales waste as a low cost and eco-friendly adsorbent for removal of an azo dye: Equilibrium, kinetic and thermodynamic studies. Bioresource Technology, 245: 656-664. https://doi.org/10.1016/j.biortech.2017.08.153

Peng, N., Hu, D., Zeng, J., Li, Y., Liang, L. and Chang, C. (2016). Superabsorbent Cellulose-Clay Nanocomposite Hydrogels for Highly Efficient Removal of Dye in Water. ACS Sustainable Chemistry and Engineering, 4(12): 7217-7224. https:// doi.org/10.1021/acssuschemeng.6b02178

Pokhrel, D. and Viraraghavan, T. (2004). Treatment of pulp and paper mill wastewater - A review. Science of the Total Environment, 333(1-3): 37-58. https://doi.org/10.1016/j.scitotenv.2004.05.017

Rashed, M. N. (2013). Adsorption Technique for the Removal of Organic Pollutants from Water and Wastewater. In M. Nageeb Rashed (Ed.), Organic Pollutants - Monitoring, Risk and Treatment pp. 167-194. Intech. https:// doi.org/10.5772/54048.

Salleh, M.A.M., Mahmoud, D.K., Karim, W.A.W.A. and Idris, A. (2011). Cationic and anionic dye adsorption by agricultural solid wastes: A comprehensive review. Desalination, 280(1-3): 1-13. https://doi.org/10.1016/ j.desal.2011.07.019

Shalla, A.H., Bhat, M.A. and Yaseen, Z. (2018). Hydrogels for removal of recalcitrant organic dyes: A conceptual overview. Journal of Environmental Chemical Engineering, 6(5): 5938-5949. https://doi.org/10.1016/j.jece.2018.08.063

Siddiqui, S. I., Chaudhry, S. A., Shahid-ul-Islam and Shahid-ul-Islam. (2017). Green Adsorbents from Plant Sources for the Removal of Arsenic: An Emerging Wastewater Treatment Technology. In Shahid-ul-Islam (Ed.), Plant-Based Natural Products: Deraivatives and Applications pp. 193-215. John Wiley \& Sons, Ltd. https:// doi.org/10.1002/9781119423898.ch10

Siddiqui, S.I., Fatima, B., Tara, N., Rathi, G. and Chaudhry, S.A. (2019). Recent advances in remediation of synthetic dyes from wastewaters using sustainable and low-cost adsorbents. The Impact and Prospects of Green Chemistry for Textile Technology. Elsevier Ltd. https:/ / doi.org/10.1016/b978-0-08-102491-1.00015-0

Singh, H., Chauhan, G., Jain, A.K. and Sharma, S.K. (2017). Adsorptive potential of agricultural wastes for removal of dyes from aqueous solutions. Journal of Environmental Chemical Engineering, 5(1): 122-135. https://doi.org/10.1016/ j.jece.2016.11.030

Slimani, R., El Ouahabi, I., Abidi, F., El Haddad, M., Regti, A., Laamari, M.R. and Lazar, S. (2014). Calcined eggshells as a new biosorbent to remove basic dye from aqueous solutions: Thermodynamics, kinetics, isotherms and error analysis. Journal of the Taiwan Institute of Chemical Engineers, 45(4): 1578-1587. https://doi.org/10.1016/j.jtice.2013.10.009

Somasekhara Reddy, M.C. and Nirmala, V. (2017). Bengal gram seed husk as an adsorbent for the removal of dyes from aqueous solutions - Equilibrium studies. Arabian Journal of Chemistry, 10: S2406-S2416. https://doi.org/10.1016/ 
j.arabjc.2013.09.002

Tanyildizi, M.Ş. (2011). Modeling of adsorption isotherms and kinetics of reactive dye from aqueous solution by peanut hull. Chemical Engineering Journal, 168(3): 1234-1240. https:/ / doi.org/10.1016/j.cej.2011.02.021

Tehrani-Bagha, A.R., Mahmoodi, N.M. and Menger, F.M. (2010). Degradation of a persistent organic dye from colored textile wastewater by ozonation. Desalination, 260(1-3): 34-38. https://doi.org/10.1016/j.desal.2010.05.004

UNESCO. (2017). Facts and Figures-Water pollution is on the rise glablly. Retrieved December 3, 2019, from http:// www.unesco.org/new/en/natural-sciences/environment/water/wwap/facts-and-figures/all-facts-wwdr3/fact-15water-pollution/

Vergili, I., Kaya, Y., Sen, U., Gönder, Z.B. and Aydiner, C. (2012). Techno-economic analysis of textile dye bath wastewater treatment by integrated membrane processes under the zero liquid discharge approach. Resources, Conservation and Recycling, 58: 25-35. https://doi.org/10.1016/j.resconrec.2011.10.005

Wakkel, M., Khiari, B. and Zagrouba, F. (2019). Textile wastewater treatment by agro-industrial waste: Equilibrium modelling, thermodynamics and mass transfer mechanisms of cationic dyes adsorption onto low-cost lignocellulosic adsorbent. Journal of the Taiwan Institute of Chemical Engineers, 96: 439-452. https://doi.org/10.1016/j.jtice.2018.12.014

Walker, G. M., Hansen, L., Hanna, J. A. and Allen, S. J. (2003). Kinetics of a reactive dye adsorption onto dolomitic sorbents. Water Research, 37(9): 2081-2089. https://doi.org/10.1016/S0043-1354(02)00540-7

Weber, W.J. and Moris, J.C. (1963). Kinetics of Adsorption on Carbon from Solution. Journal of the Sanitary Engineering Division. 89(2): 31-60.

Yang, M. (2011). A current global view of environmental and occupational cancers. Journal of Environmental Science and Health Part C Environmental Carcinogenesis and Ecotoxicology Reviews, 29(3): 223-249. https:// doi.org/10.1080/10590501.2011.601848

Zhao, B., Xiao, W., Shang, Y., Zhu, H. and Han, R. (2017). Adsorption of light green anionic dye using cationic surfactantmodified peanut husk in batch mode. Arabian Journal of Chemistry, 10: S3595-S3602. https://doi.org/10.1016/ j.arabjc.2014.03.010

Cite this chapter as: Adelodun, B., Ajibade, F.O., Abdulkadir, T.S., Bakare, H.O. and Choi, K.S. (2020). SWOT analysis of agro waste-based adsorbents for persistent dye pollutants removal from wastewaters. In: Environmental Degradation: Causes and Remediation Strategies, Volume 1, Eds. Kumar, V., Singh, J. and Kumar, P., pp. 88-103, https://doi.org/10.26832/aesa-2020-edcrs-07 